\title{
ARTICLE
}

Received 10 Apr 2016 | Accepted 21 Dec 2016 | Published 24 Feb $2017 \quad$ DOl: 10.1038/ncomms14393 OPEN

\section{Sponge-associated bacteria mineralize arsenic and barium on intracellular vesicles}

Ray Keren ${ }^{1, \star}$, Boaz Mayzel $^{1, \star}$, Adi Lavy${ }^{1}$, Iryna Polishchuk ${ }^{2}$, Davide Levy², Sirine C. Fakra ${ }^{3}$, Boaz Pokroy ${ }^{2}$ \& Micha $\|^{1}{ }^{1}$

Arsenic and barium are ubiquitous environmental toxins that accumulate in higher trophiclevel organisms. Whereas metazoans have detoxifying organs to cope with toxic metals, sponges lack organs but harbour a symbiotic microbiome performing various functions. Here we examine the potential roles of microorganisms in arsenic and barium cycles in the sponge Theonella swinhoei, known to accumulate high levels of these metals. We show that a single sponge symbiotic bacterium, Entotheonella sp., constitutes the arsenic- and barium-accumulating entity within the host. These bacteria mineralize both arsenic and barium on intracellular vesicles. Our results indicate that Entotheonella sp. may act as a detoxifying organ for its host.

\footnotetext{
${ }^{1}$ Department of Zoology, George S. Wise Faculty of Life Sciences, Tel Aviv University, Tel Aviv 69978, Israel. ${ }^{2}$ Faculty of Materials Engineering and the Russel Berrie Nanotechnology Institute, Technion, Israel Institute of Technology, Haifa 32000, Israel. ${ }^{3}$ Advanced Light Source, Lawrence Berkeley National Lab, Berkeley, California 94720, USA. * These authors contributed equally to this work. Correspondence and requests for materials should be addressed to R.K. (email: mr.ray.keren@gmail.com).
} 
$\mathrm{M}$ icroorganisms greatly influence $\operatorname{arsenic}^{1}$ and barium $^{2}$ geochemical cycles. Of the two, arsenic is extremely toxic to most life forms, except for a few arsenic-respiring bacteria ${ }^{1}$ and eukaryotic hyperaccumulators ${ }^{3}$. Most soluble forms of arsenic ${ }^{3}$, as well as the barium ion ${ }^{4}$, are potent bioavailable toxins. However, their bioavailability decreases when assimilated into organic forms, or by mineralization ${ }^{4,5}$.

Soluble barium concentrations in surface seawater are typically $10 \mu \mathrm{gl} \mathrm{l}^{-1}$ and present in two states: most is found as a divalent barium ion and a small amount as undissociated barite $\left(\mathrm{BaSO}_{4}\right)^{6}$. Barite is primarily detected as particulate matter and is especially enriched in areas of high microplankton productivity ${ }^{6}$. Arsenic is a common trace element $\left(\sim 2 \mu \mathrm{gl}^{-1}\right)$ in marine environments. In the oxygenated seawater where Theonella swinhoei is found, arsenate is the dominant form of arsenic, followed by arsenite and a minute amount of methylated arsenic ${ }^{3}$. Most marine organisms accumulate arsenic to some extent, usually as organoarsenicals ${ }^{3}$. Although both arsenic and barium can be detected in all tissues, their distribution is not homogenous. Toxic element concentration is highest in tissues and organs dedicated to detoxification and excretion ${ }^{3,7}$.

Sponges are ancient metazoans ${ }^{8}$, of paramount significance to benthic communities ${ }^{9}$. Inhabiting all types of marine ecosystems, sponges contribute to global carbon ${ }^{10}$, nitrogen ${ }^{11}$ and silicon ${ }^{12}$ cycles. Sponges are filter feeders, filtering seawater up to 50,000 times their body volume daily ${ }^{13}$, resulting in high exposure to trace elements. Several studies have shown that sponges have the tendency, differing by species, to accumulate trace elements ${ }^{14-17}$. Sponge-associated bacteria are known to contribute to important elemental cycling in sponges, namely carbon, nitrogen and sulfur $^{8}$, but their role in trace element cycling is rarely studied $^{18,19}$.

Recent trace element analyses of Red Sea (Gulf of Aqaba) demosponges singled out Theonella swinhoei, a common Indo-Pacific sponge ${ }^{20}$, as a hyperaccumulator of arsenic (As) and barium $(\mathrm{Ba})^{14}$. The concentrations of arsenic $\left(8,600 \mu \mathrm{gg}^{-1}\right)$ and barium $\left(13,400 \mu \mathrm{gg}^{-1}\right)$ are the highest concentrations recorded in any organism from an uncontaminated environment.

Symbiotic bacteria comprise approximately half the volume of T. swinhoe ${ }^{21}$. These include both phototrophic and heterotrophic bacteria ${ }^{21}$. The phototrophic cyanobacteria are located in a thin layer, close to the surface of the sponge, giving the host its characteristic colour. The heterotrophic bacteria reside mostly in the sponge's inner mesohyl part. While the majority of sponge-associated bacteria are unicellular ${ }^{21}$, the most abundant bacterium is filamentous and identified as Entotheonella sp. ${ }^{21,22}$. Moreover, Entotheonella sp. is considered a 'talented producer', synthesizing many of the bioactive compounds found in this sponge $^{22}$.

Because sponges lack organs and tissues, there is no apparent localization for the storage of arsenic and barium. Following the initial discovery of arsenic and barium accumulation, the sponge was separated into enriched fractions of either sponge cells or bacterial cells, revealing arsenic was localized to the bacterial fraction. Barium concentrations were also shown to be high in these fractions (although the differences were not statistically significant $)^{18}$. Culturing trials recovered numerous arsenic-tolerant, sponge-associated bacteria growing on media enriched with as much as $100 \mathrm{mM}$ arsenate ${ }^{18}$.

Here we show that a population of a single symbiotic bacterium, Entotheonella sp., appears to drive arsenic and barium accumulation in this sponge. We further demonstrate that the bacterium can mineralize both elements on intracellular membrane vesicles.

\section{Results}

Entotheonella sp. accumulates arsenic and barium. Arsenic and barium have the highest atomic weight, among elements found in the sponge $e^{14}$. Thus, their accumulation can be detected using a scanning electron microscope (SEM) with backscatter detection mode (backscattered electron). Our preliminary results indicated that arsenic, and to some extent barium, were accumulated by the sponge-associated bacteria ${ }^{18}$. Surprisingly, when examining the sponge using SEM $(n=4)$, we discovered that a single bacterium, identified as Entotheonella sp.22 (Fig. 1a), had the highest electron density (Fig. 1b). Using energy-dispersive X-ray spectrometry (EDS) we analysed their elemental composition and found that Entotheonella sp. contained both arsenic (6.07\% weight ratio) and barium (11.7\% weight ratio). The filamentous bacterium Entotheonella sp. was previously described in T. swinhoei as trichomes or chains ${ }^{21,23}$, with 4 to 20 cells. However, no analysis has been made to date of the electron-dense material observed in its cells, which from our analysis we now know to be rich in barium and arsenic. Next, we used inductively coupled plasma mass spectrometry (ICP-MS) to quantify arsenic and barium in four, easily separated, cell-enriched fractions: sponge cells $\left(F_{\mathrm{SC}}\right)$, Entotheonella sp. $\left(F_{\mathrm{ENTO}}\right)$ and unicellular bacteria $\left(F_{\mathrm{BAC}}\right)$ from the inner layer. The fourth fraction was taken from the outer layer and contained Entotheonella sp. and cyanobacteria $\left(F_{\mathrm{EC}}\right)$. The three fractions enriched from the inner layer $\left(F_{\mathrm{SC}}, F_{\mathrm{ENTO}}\right.$ and $F_{\mathrm{BAC}}$ ) were tested against each other (Supplementary Table 1$)$. As the two samples containing Entotheonella sp. $\left(F_{\mathrm{ENTO}}\right.$ and $\left.F_{\mathrm{EC}}\right)$ were not independent, they were compared separately (Supplementary Table 2). We found the highest concentration of barium in $F_{\text {ENTO }}\left(26,420 \pm 6,450 \mu \mathrm{gg}^{-1}\right.$ cells dry weight, $n=5$; Fig. 1c). Permutated analysis of variance (ANOVA) followed by Tukey's post hoc grouping showed $F_{\text {ENTO }}$ barium concentration to be significantly higher than $F_{\mathrm{BAC}}$ (Supplementary Table 1 ). The difference between $F_{\mathrm{ENTO}}$ and $F_{\mathrm{SC}}$ was also tested by an exact permutation test, which showed they were significantly different $(P=0.024)$. All cell fractions contained a high arsenic concentration compared to other marine $\operatorname{taxa}^{3}$, with fractions containing Entotheonella sp. $\left(F_{\mathrm{ENTO}}\right.$ and $\left.F_{\mathrm{EC}}\right)$ displaying the highest concentration $\left(F_{\mathrm{ENTO}}: 12,072 \pm 3,740 \mu \mathrm{gg}^{-1}\right.$ cells dry weight, $n=5 ; F_{\mathrm{EC}}$ : $12,142 \pm 3,406 \mathrm{\mu g} \mathrm{g}^{-1}$ cells dry weight, $n=5$; Fig. 1d). Permuted ANOVA followed by Tukey's post hoc grouping showed arsenic concentration in $F_{\text {ENTO }}$ was significantly higher than those of the other inner fractions (Supplementary Table 1). We thus deduced that $T$. swinhoei either actively retains arsenic ${ }^{14}$ or passively uptakes and sequesters at a greater rate than it can excrete $^{24}$.

Our examination revealed that Entotheonella sp. comprises $3.25 \%$ (s.e. $=0.0987$ ) of the sponge volume (see calculation in Methods), and has a volume/weight ratio of 0.478 . From this, we calculated that a $100 \mathrm{ml}$ sponge would include $1.55 \mathrm{~g}$ of Entotheonella sp., containing 7,110 $\mathrm{gg}$ of water-soluble arsenic (Supplementary Table 2). This is equivalent to the amount of arsenic found in 2,370l of seawater (according to the recorded concentration of $3 \mu \mathrm{gl}^{-1}$; ref. 18). At maximum pumping rate ${ }^{25}$, such a specimen can filter 2881 of seawater daily, reaching a maximum arsenic exposure of $864 \mu \mathrm{g}$. Thus, we propose that Entotheonella sp. acts as the accumulating and detoxifying entity in the sponge holobiont.

Entotheonella sp. mineralizes barium and arsenic. Biomineralization is usually described as either biologically controlled mineralization (BCM) or biologically induced mineralization (BIM), although intermediate forms are known ${ }^{26-28}$. BIM generally occurs extracellularly when metabolic byproducts 

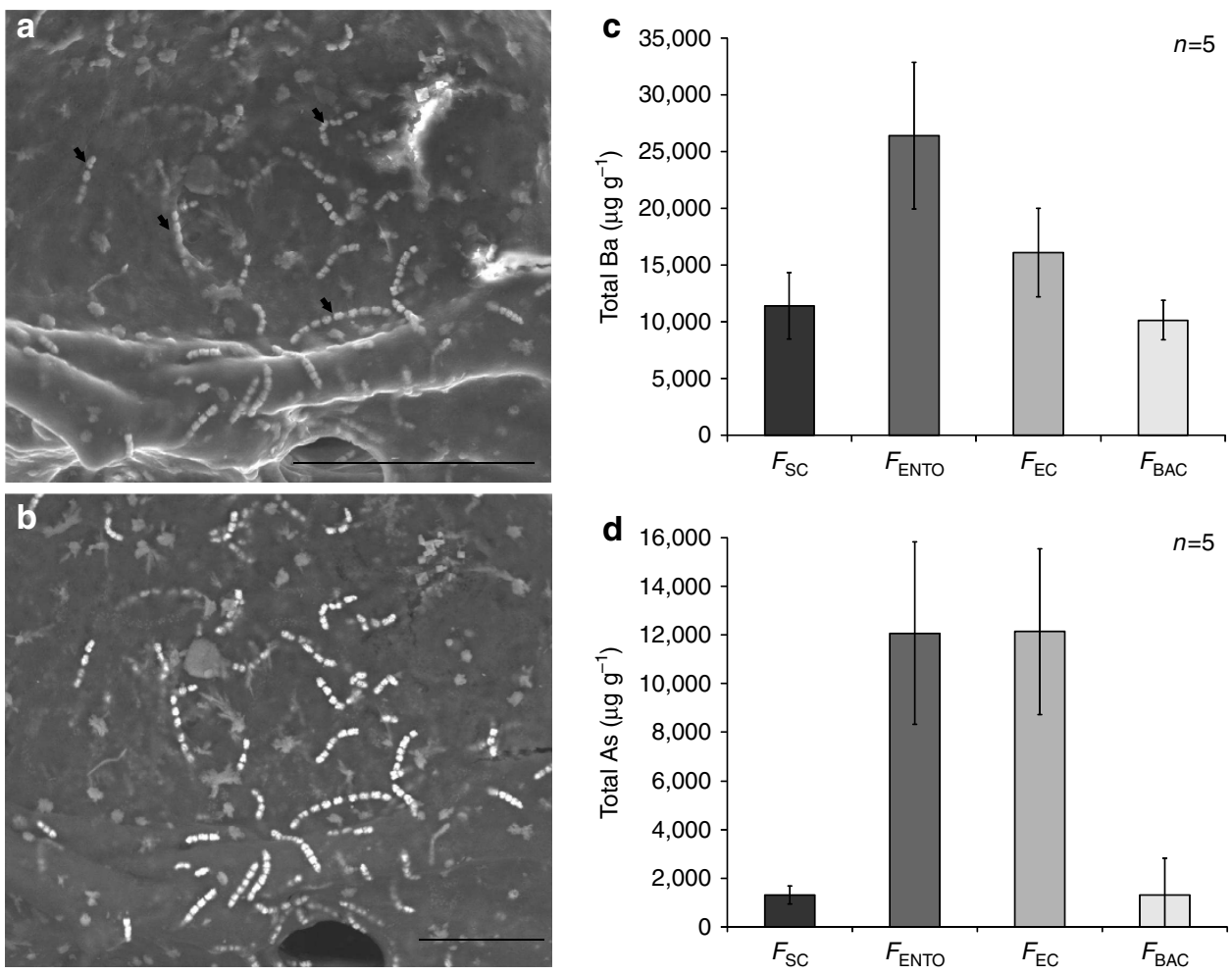

Figure 1 | Entotheonella sp. is the arsenic and barium accumulating entity in the $\boldsymbol{T}$. swinhoei holobiont. (a,b) Compatible SEM micrographs of Entotheonella sp. in sponge tissue. (a) Secondary electron detection mode with arrows indicating some of the Entotheonella sp. filaments. Scale bar, $100 \mu \mathrm{m}$. (b) Backscattered electrons detection mode reveals Entotheonella sp. filaments as the most-electron-dense objects in the sponge. Scale bar, $50 \mu \mathrm{m}$. $(\mathbf{c}, \mathbf{d})$ Dry weight concentration $\left(\mu \mathrm{g} \mathrm{g}^{-1}\right)$ of barium and arsenic (respectively) in cell-enriched fractions ( $n=5$ samples, each one from a different sponge). $F_{\mathrm{BAC}}$, unicellular bacterial cells; $F_{\mathrm{EC}}$, Entotheonella sp. with cyanobacteria; $F_{\mathrm{ENTO}}$, Entotheonella sp. cells; $F_{\mathrm{SC}}$, sponge cells. Error bars show s.e.

react with chemicals in the environment. Minerals formed this way have poor crystallinity and are often unspecific. Intracellular BIM can occur in some bacteria, even up to the point of cell lysis $^{29,30}$, but this occurs mostly in environments enriched with metal ions. These ions are mainly associated with sulfide, and precipitation is considered to be a detoxification mechanism ${ }^{28}$. $\mathrm{BCM}$ also exist in bacteria, such as magnetotactic bacteria, though is far less common than BIM. In BCM, minerals are deposited intracellularly on or within organic matrices or vesicles. The intravesicular conditions are controlled by the bacteria and are not affected by the environment. The minerals formed by BCM are well-ordered and specific.

A close look at Entotheonella sp. filaments from T. swinhoei shows that they contain multiple spherical granules inside their cells (Fig. 2a). The sphere volume is quite homogenous, averaging $0.11 \pm 0.007 \mu \mathrm{m}^{3}$ with a median volume of $0.08 \mu \mathrm{m}^{3}$ $(n=121$; Supplementary Fig. 1). Observation of thin sections of Entotheonella sp. under transmission electron microscopy (TEM) revealed that mineralization nucleates from the membrane of vesicles (Fig. 2b), thickening inwards (Fig. 2c).

To verify that the vesicle membranes are lipid-based, live Entotheonella sp. cells $(n=5)$ were stained with the fluorescent membrane stain, 3,3'-dihexyloxacarbocyanine iodide $\left(\mathrm{DiOC}_{6}\right)$ (Fig. 3a). Focused ion beam (FIB) cross-sections of the bacterium $(n=1)$ were prepared for SEM-EDS analysis. High-resolution imaging of the cross-sections shows that the mineral 'wall' is highly porous (Fig. 3b). We hypothesize that the porous nature of the sphere wall may facilitate material exchange between the core of the vesicle and the cytoplasm, via the membrane. Analysis of the elemental composition of the mineral wall and the vesicle core was conducted (Fig. 3c). Barium was significantly higher in sphere wall than in the core (two-sample permutation test using
Welsh's $t$-test, two-sided test, $n=3, t=-3.6213, P$ value $<2.2 \mathrm{e}-16$ ). Arsenic however was similar between wall and core. The core contained more organic matter, as indicated by a substantially higher carbon presence (two-sample permutation test using Welsh's $t$-test, one-sided test, $n=3, t=4.4772$, $P$ value $=0.0471)$. Nitrogen content in the core was also significantly elevated (two-sample permutation test using Welsh's $t$-test, two-sided test, $n=3, t=3.8697, P$ value $=0.0474$ ), which might indicate the potential presence of proteins.

To determine the biomineral phase composition in Entotheonella sp., we analysed spheres using high-resolution synchrotron X-ray powder diffraction (XRD) in freeze-dried samples $(n=5)$. We found that the crystalline fraction contains several minerals.

Barite was the major phase, with arsenates and phosphates probably minor phases (Fig. 4a). Crystalline barite presence within spheres was also confirmed by high-resolution TEM examination of FIB-prepared thin section (Fig. 4b). The fast Fourier transform of the TEM image obtained from a magnification close to an individual atomic lattice layer exhibits a single crystal electron diffraction from $[-200]$ zone axis of barite. Entotheonella sp. is thus the only known prokaryote capable of intracellular barite mineralization.

The detected barite was polycrystalline, and a precise structural determination of the minor phases could not be achieved due to their poor crystallinity and the high organic matter content present in the freeze-dried samples. Aiming to improve the quality of the crystals and to eliminate the organic phase, we further subjected the samples to mild thermal annealing $\left(250^{\circ} \mathrm{C}\right.$ for $2 \mathrm{~h}$ ). The diffractogram collected after heating allowed us to detect crystalline calcium arsenate $\left(\mathrm{Ca}_{3}\left(\mathrm{AsO}_{4}\right)_{2}\right)$ and calcium sulfide phosphate $\left(\mathrm{Ca}_{10}\left(\mathrm{PO}_{4}\right)_{6} \mathrm{~S}\right)$ as minor phases (Fig. 4c). 
Quantitative phase analysis performed using the Rietveld method $^{31}$ enabled the precise quantification of each crystalline phase (weight fractions) comprising the investigated samples: $\mathrm{BaSO}_{4}$ accounted for $87 \%$ of the crystalline weight, $\mathrm{Ca}_{3}\left(\mathrm{AsO}_{4}\right)_{2}$ for $7 \%$ and $\mathrm{Ca}_{10}\left(\mathrm{PO}_{4}\right)_{6} \mathrm{~S}$ for $6 \%$.

The presence of barite and calcium arsenate were further confirmed on unprocessed 'intact' flash-frozen Entotheonella sp. samples by synchrotron X-ray microprobe analyses (X-ray fluorescence mapping, X-ray absorption spectroscopy and XRD) performed at $95^{\circ} \mathrm{K}$. The distribution of arsenic in the filaments was evident by micro-focused X-ray fluorescence ( $\mu \mathrm{XRF}$ ) mapping (Fig. 5a and inset). All arsenic K edge X-ray absorption near edge structure (XANES) spectra of Entotheonella sp. showed $\mathrm{As}(\mathrm{V})$ as the dominant valence when compared to relevant standards (Fig. 5b). Generally, the white line increases in height, shifts towards higher energy and decreases in full-width at half-maximum as the oxidation state increases ${ }^{32}$. Least-square linear combination fitting (LCF) of 39 filament spectra (Fig. 5b) to a large library of 64 arsenic reference compounds from the ALS BL 10.3.2 database was performed. Top best LCF fits using 1, 2 or 3 components consistently required non-sulfur As(III), calcium arsenates (mostly pharmacolite) and sodium arsenate and best fits were obtained using combinations of these three components. $\mu \mathrm{XRD}$ performed on some of the filaments' XANES locations showed the presence of pharmacolite (Supplementary Fig. 3).
The three-component LCF performed on 39 filaments indicated an average (rounded to full digits) of $18 \%$ As(III), $32 \%$ pharmacolite and $50 \%$ sodium arsenate. However, a precise determination of compound proportion could not be achieved for several reasons: the identity of the non-sulfur As(III) compound in unknown, the spectral fine structure of sodium arsenate varies with $\mathrm{pH}^{33}$ and concentration ${ }^{34}$ and fine spectral features vary with the degree of crystallinity. Compound abundance depended on location, as further evidenced by $\mathrm{As}(\mathrm{III}) / \mathrm{As}(\mathrm{V})$ chemical mapping, which exhibited heterogeneous distribution (Fig. 5c). LCF of $\mathrm{Ba} \mathrm{L}_{3}$ edge XANES data on the filaments (Fig. 6a) best matched barite ${ }^{35}$ whose presence was further confirmed by $\mu$ XRD (Fig. 6b). These combined results provide strong evidence of intracellular mineralization of barium (in the form of barite) and intracellular crystalline arsenic.

To determine whether the crystalline phases of barium and arsenic could explain all the measured elemental concentrations, we compared the atomic ratios of barium, sulfur and arsenic. Water-soluble element concentration (barium: $541 \mu \mathrm{gg}^{-1}$ cells; sulfur: $1,084 \mu^{-1}$ g cells; arsenic: $4,577 \mu^{-1} g^{-1}$ cells) was subtracted from the total elemental concentration and normalized by atomic weight. For crystalline barite $\left(\mathrm{BaSO}_{4}\right)$ to explain all insoluble barium the $\mathrm{Ba}: \mathrm{S}$ atomic ratio should be $\leq 1$. While our measurements showed the ratio to be $>1$ (average $=2.14 \pm 0.84$, $n=5)$, this is not significantly different from a ratio of 1
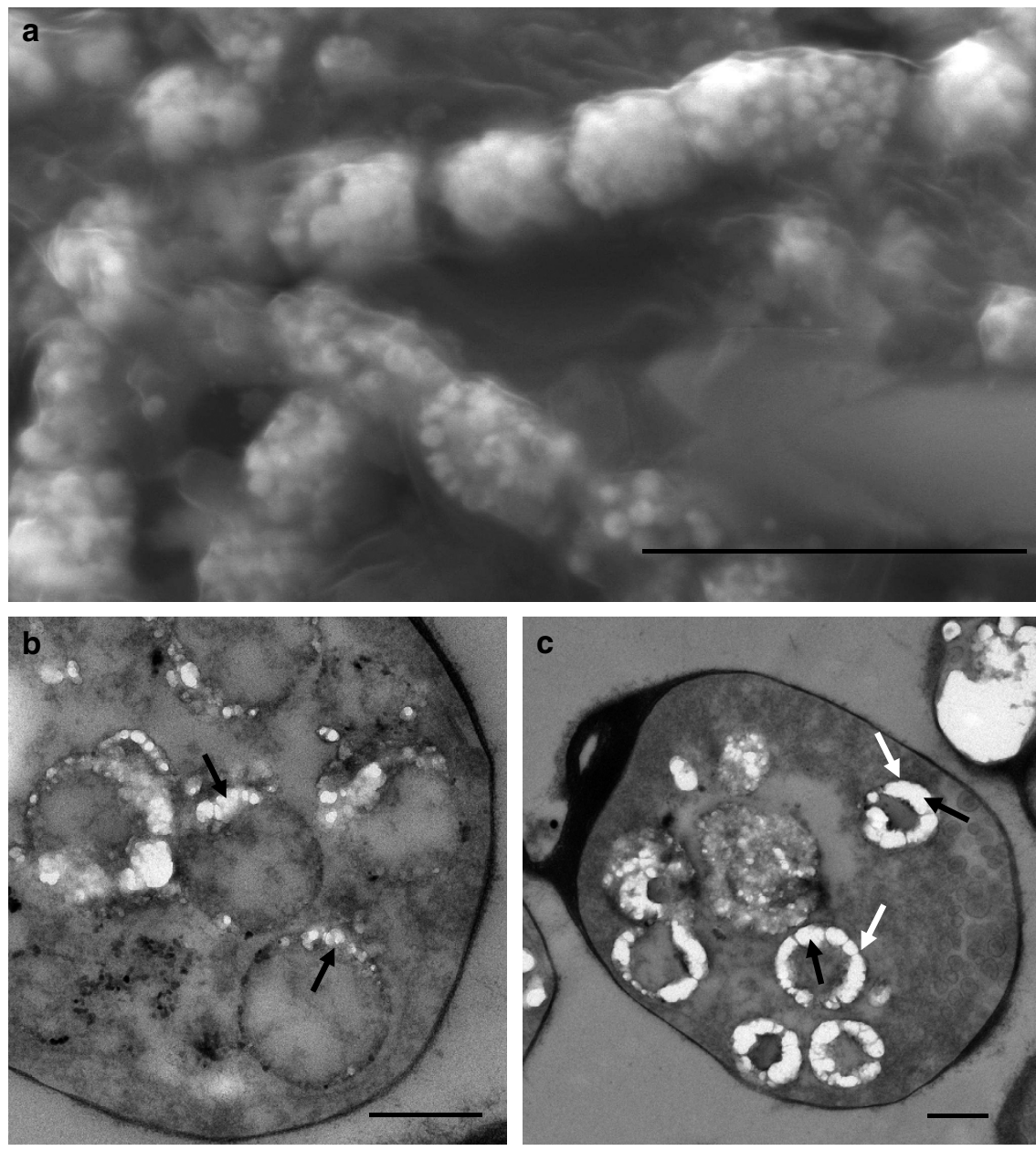

Figure 2 | Intracellular mineralization in Entotheonella sp. (a) SEM micrograph (secondary electron mode) of Entotheonella sp. showing mineralized spherical structures inside their cells. Scale bar, $10 \mu \mathrm{m}$. (b,c) TEM micrographs of thin sections of Entotheonella sp. Black arrows in $\mathbf{b}$ mark nucleation of minerals from the vesicles' membrane. Black arrows in c mark the thickening of the mineral inwards from the membrane of the vesicle (white arrows). Scale bar, $500 \mathrm{~nm}$. 
(paired $T$-test, $t=1.4212$, d.f. $=4, P$ value $=0.2283$ ). Our analysis thus showed that the majority of insoluble barium can be explained by crystalline barite. This was further confirmed by $\mathrm{Ba}$ XANES and $\mu$ XRD data (Fig. 6). Examination of crystalline arsenic is slightly more complicated. To do so, we calculated the weight ratio of crystalline barium and arsenic. Barium comprises $58.8 \%$ of barite molecular weight, and thus constitutes $51.2 \%$ of total crystalline weight. Arsenic comprises $37.7 \%$ of $\mathrm{Ca}_{3}\left(\mathrm{AsO}_{4}\right)_{2}$ molecular weight, and thus constitutes $2.6 \%$ of total crystalline weight. From the Ba:As ratio (20:1), we calculated that $1,290 \mathrm{\mu g}^{-1}$ (or 17.2\%) of the insoluble arsenic is crystalline. The poor crystallinity of arsenic and spatial variation of calcium arsenate and As(III) in the XANES fit prevents a clear identification of the amorphous arsenic solid. However, since the average ratio of calcium arsenate by XANES analysis is $32 \%$ $\left(\sim 3,850 \mathrm{\mu g} \mathrm{g}^{-1}\right.$ cells), we can say with confidence that some of the calcium arsenate is amorphous. The identity of the As(III) compound is unknown and may either be soluble or solid.

Altogether, the results indicate that Entotheonella sp. controls mineral formation within its cells to a relatively high degree. This phenomenon exhibits many of the characteristics of BCM, with the exception of the ability to mineralize finely ordered crystalline material. Thus, we conclude that Entotheonella sp. possesses an intermediate form of BCM, with some similarities to magnetotactic-like bacteria ${ }^{28}$.

Bioavailability of arsenic in Entotheonella sp. We tested the presence of arsenate (as sodium arsenate) and a compound with As(III) using the XANES analysis (Fig. 5). Since most soluble arsenic species are extremely toxic, we identified and quantified them in the enriched cell fractions from the sponge (Table 1). We separated arsenic species using ion exchange chromatography and identified them against known standards (arsenite: As(III); arsenate: As(V); monomethylarsonic acid (MMA), dimethylarsinic acid (DMA), arsenobetaine (AsB) and arsenocholine $(\mathrm{AsC})) . \mathrm{As}(\mathrm{V})$ and MMA were detected in all fractions. DMA and AsB were detected in $F_{\mathrm{SC}}, F_{\mathrm{EC}}$ and $F_{\mathrm{BAC}}$. As(III) was only detected in $F_{\mathrm{EC}}$. The absence of soluble As(III) in Entotheonella sp. means that the As(III) detected by XANES is either an amorphous solid or bound to the vesicle membranes, making it insoluble in water.

The dominant arsenic species within each fraction was tested by a permuted ANOVA, followed by a post hoc Tukey's test. We found that the arsenate concentration, as hypothesized previously $^{19}$, was significantly higher than all other arsenic species in all cell fractions, except in $F_{\mathrm{BAC}}\left(F_{\mathrm{SC}}: 892.4 \pm 284.4 \mu \mathrm{gg}^{-1}\right.$ cells, $F=9.797, P$ value $=3.37 \mathrm{e}^{-5}, F_{\text {ENTO }}: 4,498 \pm 983.4 \mu \mathrm{g} \mathrm{g}^{-1}$ cells, $F=20.7, \quad P \quad$ value $=5.2 \mathrm{e}^{-8} ; \quad F_{\mathrm{EC}}-4,301 \pm 1,228 \mu \mathrm{gg}^{-1}$ cells, $F=12.06, \quad P$ value $=6.5 \mathrm{e}^{-6} ; F_{\mathrm{BAC}}: 747 \pm 485.7 \mu \mathrm{gg}^{-1}$ cells, $F=2.48, P$ value $=0.0719$ ).

Upon testing differences in arsenate concentration among fractions, we found that $F_{\text {ENTO }}$ had a significantly higher arsenate concentration than all other cell fractions (permuted ANOVA, followed by post hoc Tukey's test, $F=10.55, P$ value $=0.00227$ ). Bacteria are reported to tolerate as much as $1 \mathrm{M}$ of arsenate (or $75,000 \mu \mathrm{gg}^{-1}$ arsenic) ${ }^{36}$ by means of continuous excretion and maintenance of low intracellular concentrations ${ }^{5}$. Our analysis indicates that Entotheonella sp. accumulates, rather than excretes, arsenate. Moreover, a statistical test (exact permutation test estimated by 999 Monte Carlo replications) showed that arsenate concentrations in Entotheonella sp. (normalized by atomic mass) are significantly higher than those of water-soluble sulfur $\left(912 \pm 205 \mu \mathrm{gg}^{-1}\right.$ cells, $P$ value $=0.024$, confidence interval $(\mathrm{CI})=0.00877,0.04534)$ and phosphorous $\left(641 \pm 169 \mu \mathrm{gg}^{-1}\right.$ cells, $P$ value $\left.=0.01, \mathrm{CI}=0.00135,0.02511\right)$,
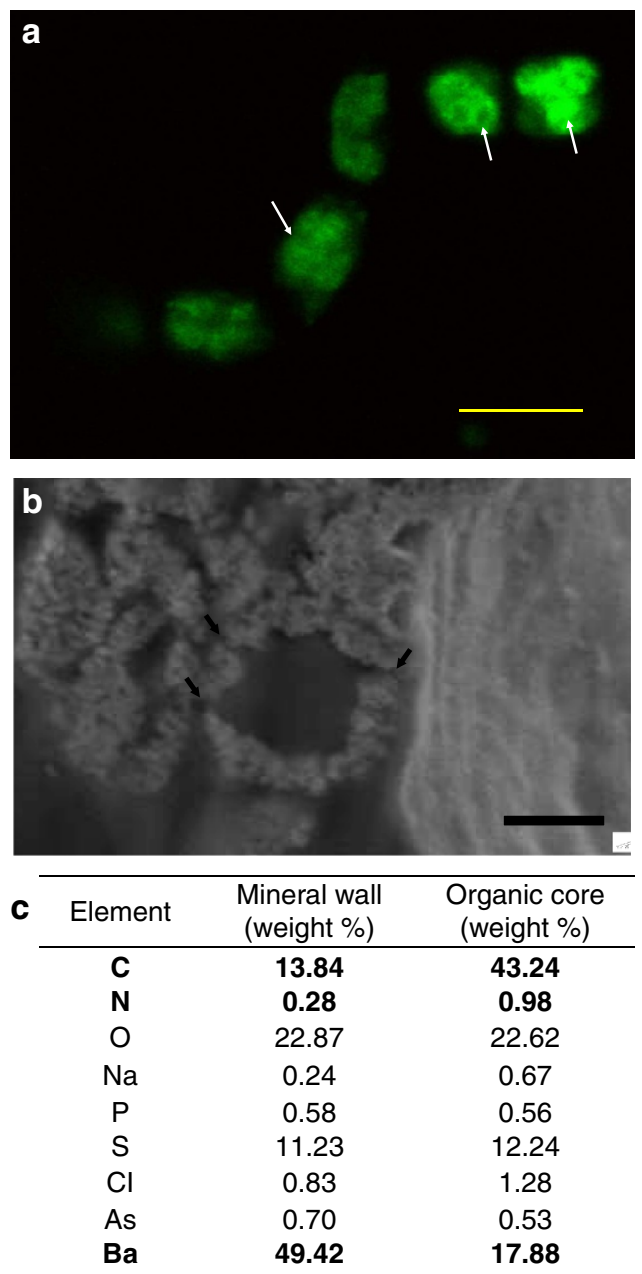

Figure 3 | Characterization of spheres in Entotheonella sp. (a) Membrane staining with $\mathrm{DiOC}_{6}$ dye (excitation (ex), $482 \mathrm{~nm}$; emission (em), $504 \mathrm{~nm}$ ) shows that the vesicles (marked by arrows) of Entotheonella sp. are lipid based. Scale bar, $5 \mu \mathrm{m}$. (b) SEM micrograph (secondary electron) of crosssection of sphere in Entotheonella sp. The sphere wall is highly porous, with resemblance of channels (marked by arrows). Scale bar, $200 \mathrm{~nm}$. (c) Average weight ratios $(n=3)$ of detected elements determined by EDS. Carbon $(\mathrm{C})$, nitrogen $(\mathrm{N})$ and barium $(\mathrm{Ba})$ are marked in bold.

both of which are essential elements ${ }^{24}$. Even with such high arsenate concentrations, Entotheonella sp. remains viable, as indicated by 5(6)-carboxyfluorescein diacetate $N$-succinimidyl ester (CFDA/SE) vital staining (Supplementary Fig. 2). If arsenic is essential to the metabolism ${ }^{37}$ of Entotheonella sp., we can reasonably expect to detect high arsenate concentrations within the cell. If Entotheonella sp. does not utilize arsenic metabolically, it should then possess highly efficient detoxification mechanisms. Mineralization of arsenic is one such mechanism, but with $4,577 \mu \mathrm{gg}^{-1}$ water-soluble arsenate, other mechanisms must also exist. We hypothesize that the soluble arsenic is localized within the core of the vesicles since arsenate does not pass through lipid membranes 5 .

Potential pathway for element accumulation in Entotheonella. To achieve mineralization, Entotheonella sp. needs to transport and concentrate the relevant elements at the site of mineralization $^{38}$. Entotheonella sp. possesses an outer sheath, which surrounds the entire filament, and two sets of membranes (Fig. 7a). The mineralized vesicles are only found in the inner 

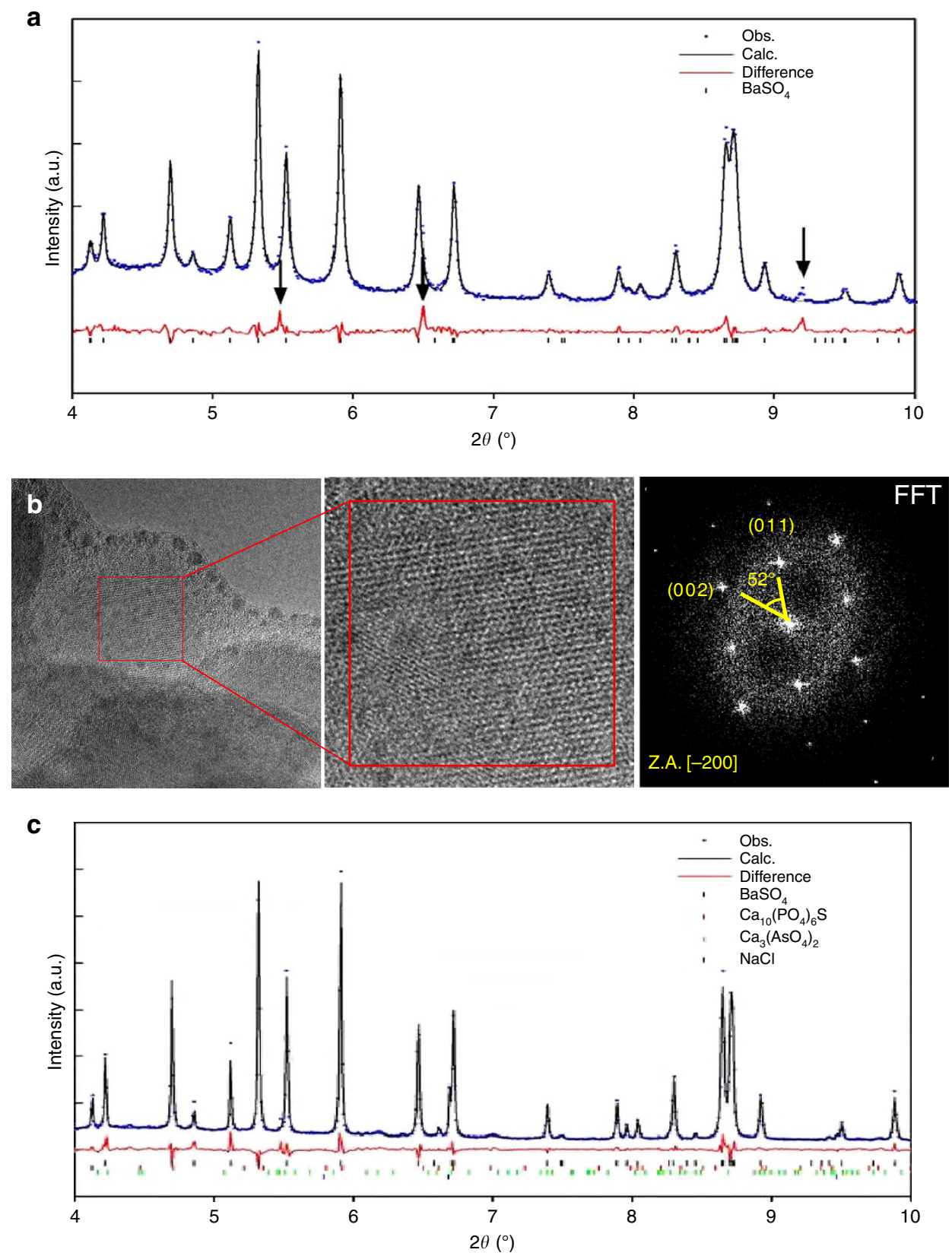

Figure 4 | XRD and TEM analysis of spheres inside Entotheonella sp. (a) Rietveld refinement plot of preheated freeze-dried Entotheonella sp. reveals the resulted fit for the observed (blue dots) and calculated (black line) diffraction patterns and the difference between them (red line). Black notches indicate the positions of the diffraction peaks of crystalline barite $\left(\mathrm{BaSO}_{4}\right)$, the major phase in the sample. Diffraction peaks highlighted by arrows in the difference curve are compatible with an arsenate or phosphate phase. These minor phases are not clearly visible in the observed diffraction pattern as they overlap with the diffraction peaks of barite. (b) HRTEM micrograph of a portion of the freeze-dried Entotheonella sp. Insert shows higher magnification image revealing the lattice, and with its Fast Fourier Transform (FFT). (c) Rietveld refinement plot of a freeze-dried Entotheonella sp. after thermal annealing, revealing minor phases of sodium chloride $(\mathrm{NaCl})$, calcium arsenate $\left(\mathrm{Ca}_{3}\left(\mathrm{AsO}_{4}\right)_{2}\right)$ and calcium sulfide phosphate $\left(\mathrm{Ca}_{10}\left(\mathrm{PO}_{4}\right)_{6} \mathrm{~S}\right)$. Observed $(\mathrm{Obs}$.), calculated (Calc.) and difference curves are presented in the same schematics as in a.

space. In the marine environment, both arsenate ${ }^{3}$ and barium ions ${ }^{6}$ are charged, so passive transport across an outer wall and two layers of lipid membranes is an unlikely explanation for the accumulation $^{39}$. In bacteria, arsenate may enter cells via phosphate transporters ${ }^{5}$, and barium ions via $\mathrm{K}^{+}$and $\mathrm{Ca}^{2+}$ channels ${ }^{40}$. Such unspecific transport mechanisms are also an unlikely accumulation path, since the aforementioned transporters favour their intended molecule. Entotheonella sp. may have yet undiscovered specific transporters for these ions. A third potential mechanism for ion transport and accumulation is pinocytosis of seawater ${ }^{41}$. Such a process is rare in bacteria, but there is some evidence of an endocytosis-like process in the genus Gemmata $^{42}$.

Observation of Entotheonella sp. reveals that the space between the two membranes contains many small vesicles (Fig. 7b). Interestingly, some vesicles contain a single membrane while others have a double membrane (Fig. 7b, green arrow). We hypothesize that these vesicles may be involved in the transport of arsenic and barium between the immediate surroundings and the inner volume of Entotheonella sp. Arsenic may be linked to the 


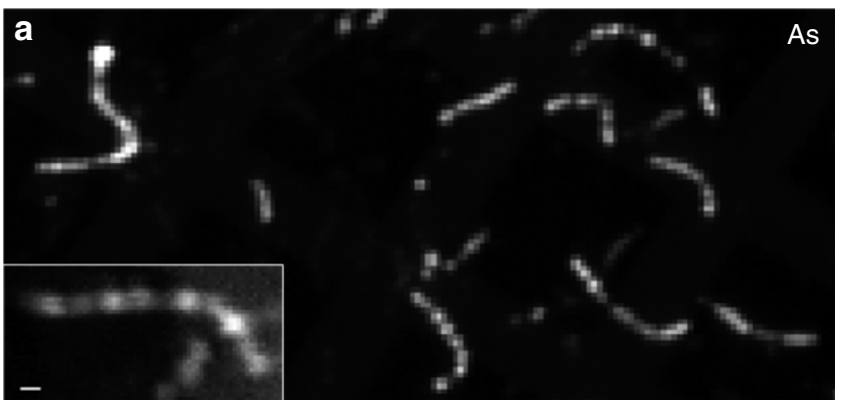

b
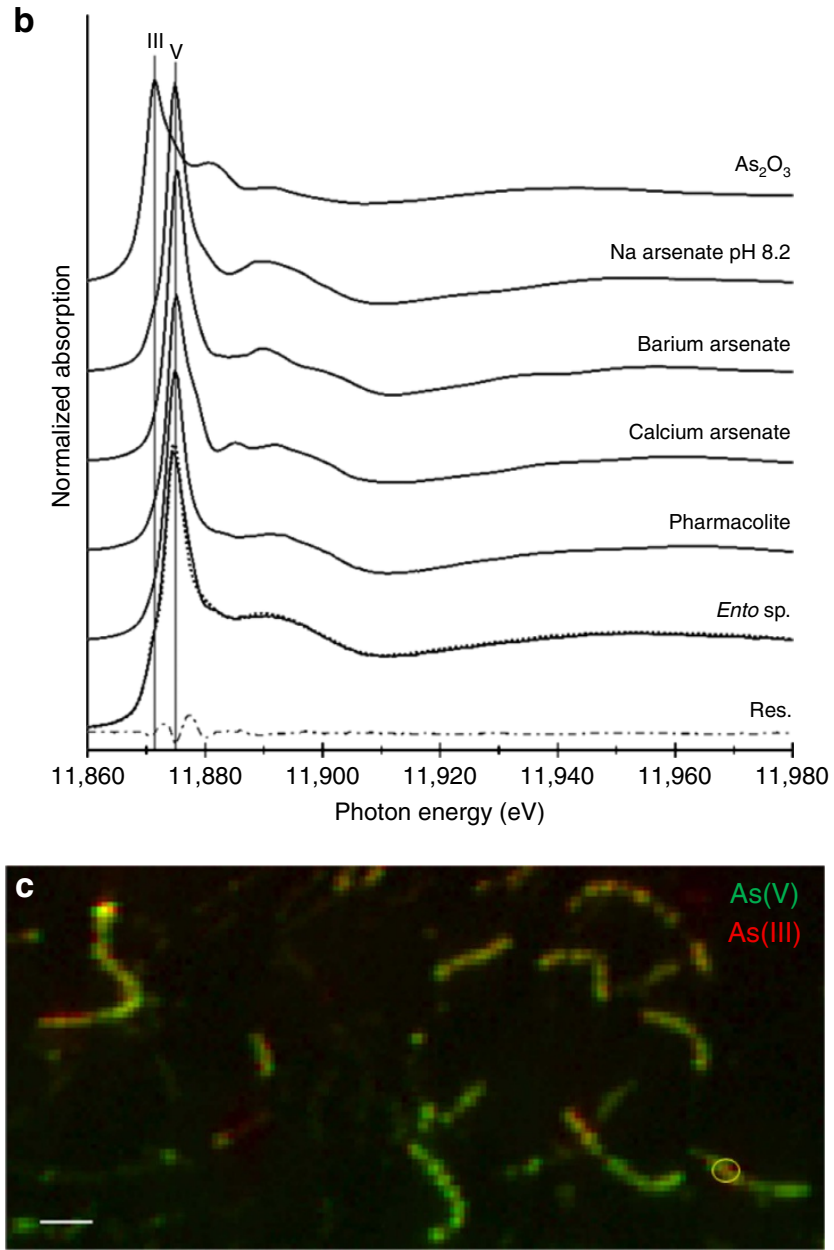

Figure 5 | X-ray microprobe analysis of arsenic in Entotheonella sp. at $95^{\circ}$ K. (a) X-ray fluorescence distribution map of As in filaments. Pixel size is $2 \mu \mathrm{m}$. Inset: As map of a single filament, pixel size is $0.8 \mu \mathrm{m}$, scale bar, $4 \mu \mathrm{m}$. (b) As K edge spectrum of Entotheonella sp. compared with As(V) and $\mathrm{As}$ (III) standards. Least-square linear combination fitting using $47 \%$ sodium arsenate, $39 \%$ pharmacolite and $14 \% \mathrm{As}_{2} \mathrm{O}_{3}$ is shown as dotted line (residuals in dashed line, norm. sum-sq $=7.6 \mathrm{e}^{-4}$ ). (c) X-ray fluorescence chemical map showing the distribution of $A s(I I I)$ and $A s(V)$ in filaments in a area. Yellow circle points to location of XANES analysis (b). Scale bar, $20 \mu \mathrm{m}$.

membranes themselves as As(III), while barium ions would likely be in the bulk liquid.

Another noteworthy aspect of the accumulation process is the merging of discrete mineralized spheres (Supplementary Fig. 4a). These spheres are discrete in the majority of cell units in Entotheonella sp. filaments, but the merging of some spheres was also observed, in some cases affecting all mineralized material $(n=9)$. Further, all cells in which full sphere merging occurred, seemed to have lost their inner membrane (Supplementary Fig. $4 b)$.

\section{Discussion}

Here we describe a host-bacterium relationship established around the accumulation and detoxification of harmful trace elements. Previously, we concluded that arsenic and barium were coaccumulated, based on statistical analyses that showed grouping of the aforementioned elements ${ }^{14}$. Here we demonstrate that both elements are localized to a specific symbiotic bacterium, Entotheonella sp. The combined results of previous ${ }^{14}$ and present research provides evidence supporting a linkage between arsenic and barium cycles in T. swinhoei, driven largely by Entotheonella sp. In past measurements of arsenic in Japanese sponges, a Theonella sp. was found to have the highest arsenic concentration among analysed species, with $157 \mu \mathrm{gg}^{-1}$ (only water-soluble arsenic was measured $)^{43}$. While this is much lower than the concentration we found in Red Sea T. swinhoei, it is still relatively high for sponges. Interestingly, the concentration of AsB in the Japanese Theonella sp. equals the concentration of AsB in $F_{\mathrm{EC}}$. It is compelling to speculate that at some point in the T. swinhoei evolution and dispersion towards the Red Sea, Entotheonella sp. evolved in a way that significantly affected the arsenic cycle of the sponge.

Multicellular organisms can detoxify arsenic by accumulating and precipitating the element in designated excretion and detoxification tissues ${ }^{7}$. T. swinhoei does not possess differentiated tissues but our results suggest an alternative detoxification mechanism. Entotheonella sp., residing within the sponge's mesohyl, can accumulate ten times more water-soluble arsenic than the sponge's daily exposure to soluble arsenic, which it then mineralizes. Therefore, we propose that Entotheonella sp. may function, to some extent, as a detoxifying organ for T. swinhoei. Excretion of Entotheonella sp. by the sponge is unlikely, as past measurements have shown very few bacterial cells in this sponge's excurrent ${ }^{25}$.

Other microorganisms reported to accumulate arsenic have a much lower arsenic concentration ${ }^{44}$ or maintain a high concentration due to elevated arsenic in the environment ${ }^{45}$ Total arsenic concentration in Entotheonella sp. $\left(12,000 \mu \mathrm{g} \mathrm{g}^{-1}\right.$ cells) is among the highest measured in any known organism ${ }^{3}$ or surficial deposit ${ }^{46}$. Furthermore, we show that Entotheonella sp. can form intracellular crystalline arsenic, and mineralize barium intracellularly. The only other arsenic biogenic mineral so far described is orpiment ${ }^{38}$, thus biomineralization of calcium arsenate by Entotheonella sp. adds to the ever growing list of biominerals. Another prokaryote (Desulfotomaculum auripigmentum) precipitates arsenic intracellularly ${ }^{47}$, but amorphously, localized near the cell membrane and eventually excreted. Our analyses indicate that Entotheonella sp. mineralizes arsenic and barium solely intracellularly, without excretion.

Still, some questions remain unanswered. The origin of the membranes on which the biomineralization occurs remains to be elucidated. Whether they result from invagination of the plasma membrane or constitute a separate synthesized membrane ${ }^{48}$ is unknown. The exact mechanism of element accumulation and transport to the site of mineralization is another subject for which future research may provide answers. However, it is clear that Entotheonella sp. possesses a unique bacterial system for element accumulation and mineralization. The formation of the biominerals might contribute to detoxification, but they could also play other, yet unknown functions.

\section{Methods}

Sample collection. We collected samples of $T$. swinhoei $(n=12)$ from the Red Sea $\left(34^{\circ} 55^{\prime} 02^{\prime \prime} / 29^{\circ} 60^{\prime} 05^{\prime \prime}\right)$, by SCUBA diving at $15-30 \mathrm{~m}$ depth 

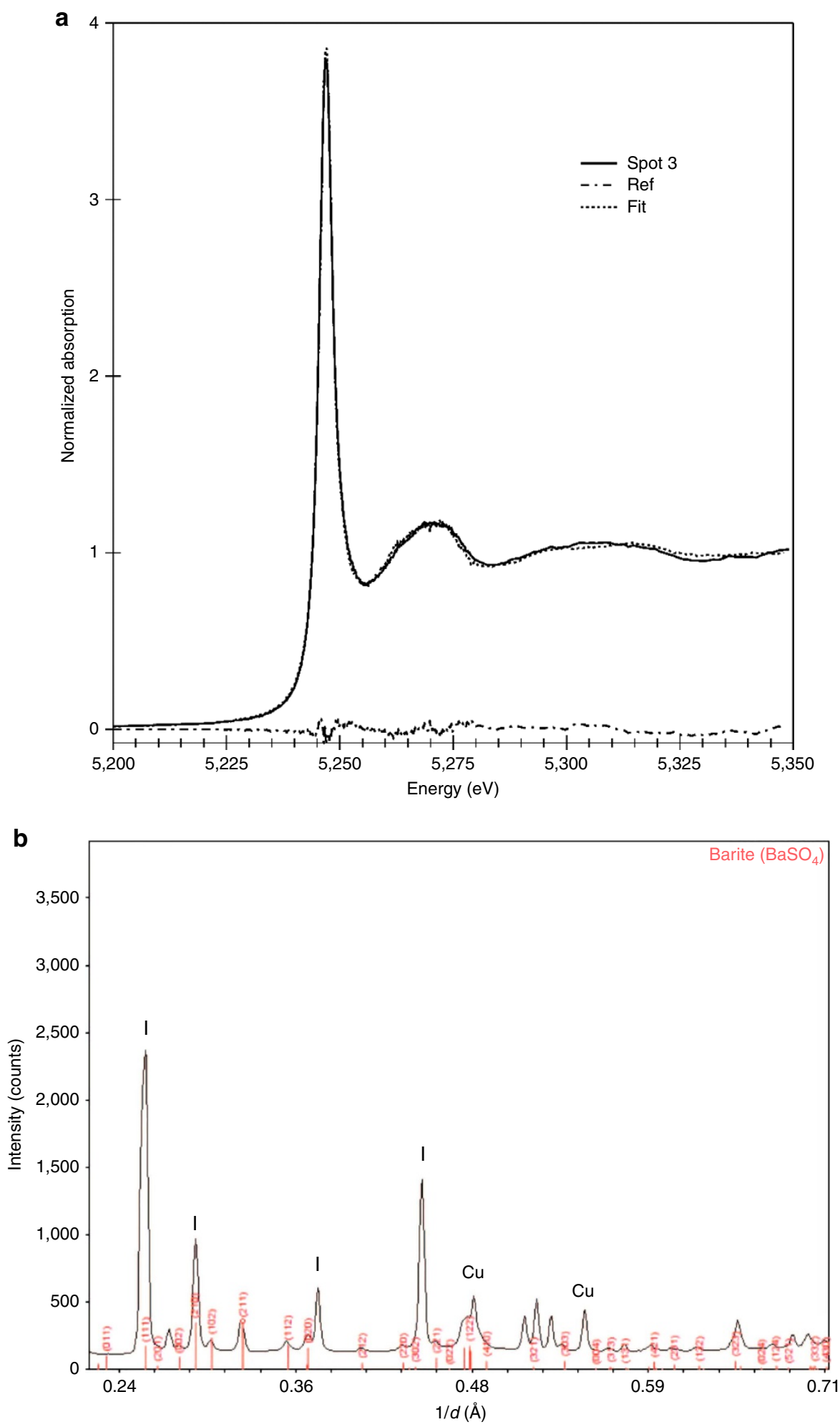

Figure 6 | X-ray microprobe analysis of barium in Entotheonella sp. at $95^{\circ} \mathbf{K}$. (a) Ba $\mathrm{L}_{3}$ edge XANES on a filament (spot3) along with LCF fit (dotted line) to $100 \%$ barite (residuals in dashed line, norm. sum-sq $=3.54 \mathrm{e}^{-4}$ ). $(\mathbf{b})$ Indexing of the XRD pattern recorded at $17 \mathrm{keV}$ at that location confirms the presence of crystalline barite. I- peaks from Ice crystals; $\mathrm{Cu}$ - peaks from copper grid.

(permit no.: 2013/40172; Israel Nature and Parks Authority). Sponges were identified by visual and tactile characteristics underwater. In the lab we further inspected the inner tissue visually. Final identification was based on the presence of Entotheonella sp. and typical microdesma spicules under light microscope. We processed the samples immediately after collection at the Interuniversity Institute for Marine Sciences in Eilat, Israel. Work was performed under sterile conditions in a laminar flow hood. Before processing we thoroughly rinsed the sponges with sterile calcium-magnesium-free artificial seawater (CMF-ASW-NaCl $26.22 \mathrm{~g}, \mathrm{KCl} 0.67 \mathrm{~g}, \mathrm{Na}_{2} \mathrm{SO}_{4} 4.62 \mathrm{~g}, \mathrm{NaHCO}_{3} 0.21 \mathrm{~g}$,

$\mathrm{Na}$ EDTA $0.37 \mathrm{~g}, \mathrm{ddH}_{2} \mathrm{O} 1 \mathrm{~L}$ set to $\mathrm{pH}$ 8) to wash off epibionts and transient bacteria.

Methods for cell separation and subsequent quantitative analysis, XRD, staining, X-ray microprobe analysis and cryogenic scanning electron microscopy (cryo-SEM) are described below. 
Table 1 | Identification and quantification ( $\mu \mathrm{gg}^{-1} \pm$ s.e.) of soluble arsenic species in cell fractions.

\begin{tabular}{lcccc} 
As species & $\boldsymbol{F}_{\mathbf{S C}}$ & $\boldsymbol{F}_{\mathbf{E N T O}}$ & $\boldsymbol{F}_{\mathbf{E C}}{ }^{\star}$ & \multicolumn{1}{c}{$\boldsymbol{F}_{\mathbf{B A C}}$} \\
\hline As $(I I I)$ & $0( \pm 0)$ & $0( \pm 0)$ & $7.9( \pm 2.8)$ & $0.6( \pm 1.3)$ \\
As $(\mathrm{V})$ & $892( \pm 284)^{\dagger}$ & $4,498( \pm 983)^{\ddagger}$ & $4,301( \pm 1,228)^{\dagger}$ & $747( \pm 549)$ \\
MMAs & $9.5( \pm 3.4)$ & $78.9( \pm 14.1)$ & $42.6( \pm 11.3)$ & $9.8( \pm 5.1)$ \\
DMAs & $0.2( \pm 0.2)$ & $0( \pm 0)$ & $2.4( \pm 1.7)$ & $0.8( \pm 0.8)$ \\
AsB & $1.4( \pm 0.4)$ & $0( \pm 0)$ & $136( \pm 12)$ & $2.6( \pm 5.3)$
\end{tabular}

ANOVA, analysis of variance; $\mathrm{AsB}$, arsenobetaine; $\mathrm{As}(\mathrm{III})$, arsenite; $\mathrm{As}(\mathrm{V})$, arsenate; $\mathrm{DMA}$, dimethylarsinic acid; $F_{\mathrm{BAC}}$, bacteria-enriched fraction; $F_{\mathrm{EC}}$, Entotheonella sp. and Cyanobacteria-enriched fraction; $F_{\mathrm{ENTO}}$, Entotheonella sp.-enriched fraction; $F_{\mathrm{SC}}$, sponge cell-enriched fraction; HSD, honest significant difference; $M$ MA, monomethylarsonic acid.

${ }^{\star} F_{\mathrm{EC}}$ was excluded from among permuted ANOVA analysis, failing the independency assumption. $F_{\mathrm{EC}}$ was tested only for within difference in As species.

†Denotes significant difference for arsenic species tested within a given cell fraction. Testing was conducted by permuted ANOVA test and Tukey's HSD post hoc grouping.

$\ddagger$ Denotes significant difference for arsenic species tested among the cell fractions. Testing was conducted by permuted ANOVA test and Tukey's HSD post hoc grouping.

SEM-EDS sample preparation and analysis. We cut small pieces of sponge samples for energy dispersive X-ray spectrometry with SEM (SEM-EDS) using sterile scalpel blades. We included the cyanobacteria-rich outer layer and the dense endoderm. We fixed the samples in $2.5 \%$ glutaraldehyde (in CMF-ASW) and kept them in the dark at $4{ }^{\circ} \mathrm{C}$ until used. Fixed sponge samples were dehydrated by an ethanol gradient series ( $50 \% \mathrm{EtOH}$ for $30 \mathrm{~min}, 70 \% \mathrm{EtOH} 8 \mathrm{~h}, 100 \% \mathrm{EtOH} 30 \mathrm{~min}$ ), followed by critical point drying and coating with carbon. Imaging and elemental analysis were performed using a High-Resolution SEM (HR-SEM; ULTRA Plus; Zeiss, Oberkochen, Germany) equipped with INCA (Oxford Instruments, England) EDS. SEM images were captured at different acceleration voltages using an Evehart Thornley secondary electron detector, enabling investigation of the surface topography and an energy selective backscatter detector suiTable for obtaining a clear compositional contrast (Z-contrast). EDS spectra were collected at points of interest using the accelerating voltage of $10 \mathrm{keV}$ at the working distance of $6 \mathrm{~mm}$. Quantitative analysis was performed using the conventional correction procedure included in the INCA software. Final results were normalized to $100 \%$ and presented as a relative ratio of elements mass (weight \%). Cross-sectioning of $F_{\text {ENTO }}$ was performed using an FEI Strata 400 S dual-beam FIB, which is a fully digital field emission scanning electron microscope equipped with FIB technology. FIB effectively enables the preparation of cross-sectioned samples by cutting a particular part of the examined object in the required direction.

Cell separation. We separated T. swinhoei $(n=5)$ into enriched cellular fractions based on well-established differential centrifugation protocols ${ }^{22,49}$, with some changes. First, we cut off the outer part, containing cyanobacteria, from the inner part of the sponge, using a sterile scalpel (further processing of the two parts was done separately).

We divided the inner part of the sponge into three cell-enriched fractions: sponge-enriched fraction $\left(F_{\mathrm{SC}}\right)$, Entotheonella sp.-enriched fraction $\left(F_{\mathrm{ENTO}}\right)$ and unicellular bacteria-enriched fraction $\left(F_{\mathrm{BAC}}\right)$. From the outer part of the sponge, we separated a fourth fraction, containing Entotheonella sp. and cyanobacteria $\left(F_{\mathrm{EC}}\right)$. We used all four cell fractions, from five sponge samples, for quantitative elemental analysis. From the same sponge samples, we took aliquots of $F_{\text {ENTO }}$ for XRD, TEM and cell staining. We collected the Entotheonella sp. fraction for cryo-SEM from two independent sponge samples. Entotheonella sp. for X-ray microprobe analysis originated from two additional independent sponge samples.

To enrich each fraction, we homogenized sponge samples in a juicer (Moulinex, France) with 11 of CMF-ASW and agitated the homogenate by stirring to disassociate cells. Cell agitation was conducted over three rounds of $2 \mathrm{~min}$ stirring and $2 \mathrm{~min}$ rest, ending with $10 \mathrm{~min}$ settling time. After settling, we filtered the supernatant through a nylon mesh $(50 \mu \mathrm{m}$ pore size $)$ into a clean collection conical flask. We resuspended the settled material in 11 of CMF-ASW and repeated the agitation and filtering steps, adding the filtered supernatant from the second round to the collection conical flask. The leftover settled material, after the two rounds of agitation and filtering, was the fraction enriched in sponge cells (fraction $F_{\mathrm{SC}}$ ). We continued to separate the bacterial fractions from the supernatant. From the inner parts of $T$. swinhoei, we pelleted fraction $F_{\text {ENTO }}$ by centrifugation of the supernatant at $150 \mathrm{~g}$, and transferred the supernatant to a new tube. We pelleted fraction $F_{\mathrm{BAC}}$ by centrifugation of the supernatant at $7,000 \mathrm{~g}$, discarding the supernatant at the end. From the outer parts of $T$. swinhoei we pelleted fraction $F_{\mathrm{EC}}$ by centrifugation of the supernatant at $300 \mathrm{~g}$, discarding the supernatant at the end. All cell fraction samples for quantitative and XRD analysis were kept at $-80^{\circ} \mathrm{C}$, followed by lyophilization. Samples for staining, cryo-SEM and X-ray microprobe analysis were kept in CMF-ASW in the dark at $4{ }^{\circ} \mathrm{C}$ until used (within $24 \mathrm{~h}$ of sampling). Samples for TEM were fixed in $2.5 \%$ glutaraldehyde (in CMF-ASW) and kept in the dark at $4{ }^{\circ} \mathrm{C}$ until used.

Computation of dry weight to volume for Entotheonella sp. We calculated the volume of Entotheonella sp. in the sponge from image analysis of histological slides ( ix slides prepared in previous years ${ }^{20}$ ) of two sponge specimens. We obtained at least 11 images at magnification $\times 20$ from randomly chosen areas of the sponge section of each slide (total of 67 images). The total sponge volume was calculated
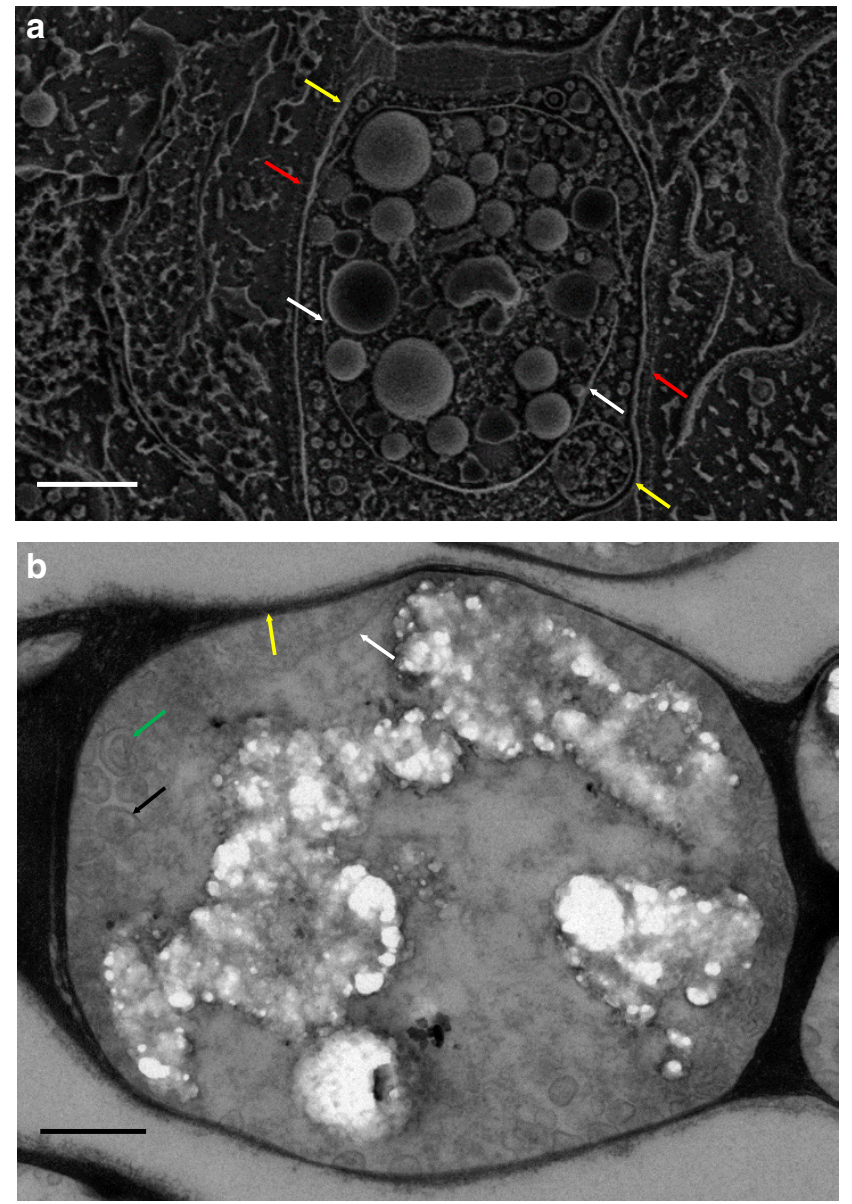

Figure 7 | Membrane system of Entotheonella sp. (a) Cryo-SEM micrograph of freeze-fractured Entotheonella sp. filament. Red arrows mark the filament sheath. Yellow arrows mark the outer membrane. White arrows mark the internal membrane harbouring the mineralized spheres. Scale bar, $1 \mu \mathrm{m}$. (b) TEM micrograph of thin sections of Entotheonella sp. showing vesicles in the space between the two membranes. Yellow arrow marks the outer membrane. White arrow marks the internal membrane. Black arrow marks a single membrane vesicle. Green arrow marks a double membrane vesicle. Scale bar, $500 \mathrm{~nm}$.

from the area observed and a depth of $2 \mu \mathrm{m}$ (the diameter of Entotheonella sp. filaments). The surface area of Entotheonella sp. in a given image was measured using the ICY software ${ }^{50}$ and the volume, assuming a cylinder shape. To compute the weight-to-volume ratio of Entotheonella sp., we collected a $0.25 \mathrm{ml}$ bacterial pellet by centrifugation and measured its weight after lyophilization.

Quantitative elements analysis. Form each cell fraction, we aliquoted a $600 \mathrm{mg}$ dry weight sample and sent it to Brooks Applied Labs (WA, USA) for elemental 
analysis. The following measurements were conducted: total elemental concentration of arsenic, barium, sulfur and phosphorous; total water-soluble elemental concentration of arsenic, barium, sulfur and phosphorous; speciation of water-soluble arsenic forms.

Total element extraction for analysis. Elements were extracted by nitric acid $\left(\mathrm{HNO}_{3}\right)$ digestion, following the EPA method $3050 \mathrm{~B}^{51}$ with $50-100 \mathrm{mg}$ (dry weight) of the cell fraction. Samples were placed in polypropylene centrifuge tubes and heated in concentrated $\mathrm{HNO}_{3}$ to $95^{\circ} \mathrm{C}$ for $15 \mathrm{~min}$ on a hot-block apparatus. Once cooled, additional $\mathrm{HNO}_{3}$ was added and the samples were reheated to $95^{\circ} \mathrm{C}$ for $30 \mathrm{~min}$, during which the formation of brown fumes was observed. This step was repeated until no fume formation was detected, and ended with $2 \mathrm{~h}$ incubation at $95^{\circ} \mathrm{C}$. Once acidic digestion was completed, $\mathrm{H}_{2} \mathrm{O}_{2}(30 \%)$ was added to the solution in aliquots and gassing was monitored until it subsided to a minimum, or sample appearance remained unchanged. An additional $2 \mathrm{~h}$ of incubation was allowed to reduce solution volume before it was cooled to room temperature. Before analysis, samples were diluted in $\mathrm{ddH}_{2} \mathrm{O}$ and filtered to remove any particulate matter.

Water-soluble element extraction for analysis. Extraction was based on a previously published protocol ${ }^{43}$ and conducted with $50-100 \mathrm{mg}$ (dry weight) of the cell fraction. Samples were placed in polypropylene centrifuge tubes and soluble compounds were extracted in $10 \mathrm{ml}$ of water:MeOH $\left(1: 1 \mathrm{vv}^{-1}\right)$ by shaking at 80 r.p.m. for 2 h. The sample was then centrifuged and divided in half. Half of the supernatant $(5 \mathrm{ml})$ was filtered $(0.45 \mu \mathrm{m})$ and directly measured. The other half was transferred with the pellet to a hot-block apparatus (set at $95^{\circ} \mathrm{C}$ ) for $3 \mathrm{~h}$, followed by centrifugation and filtration of the supernatant $(0.45 \mu \mathrm{m})$ for measuring. The results obtained from the two water-methanol extracts associated with each sample were combined to reflect the overall extractable fraction of a given analyte.

Separation and detection of arsenic species for analysis. Aliquots of each water-methanol extract were injected onto an anion exchange column and mobilized by an alkaline $(\mathrm{pH}>7)$ gradient, following a described protocol ${ }^{52}$ Retention time for each detected arsenic species in the samples was compared to those of known standards for species identification: (1) arsenate (AsV); (2) arsenite (AsIII); (3) monomethylarsonic acid (MMA); (4) dimethylarsinic acid (DMA); (5) AsB; (6) arsenocholine (AsC). All other arsenic species identified were defined as unknown arsenic species.

Three sets of laboratory control samples and matrix spikes were prepared during the speciation extraction to monitor any potential species conversion attributable to either the applied extraction procedure or the sample matrices. The first set contained AsIII, MMA, DMA and AsB; the second set contained only AsV; and the third set contained only AsC. In addition to arsenic species, phosphate and sulfate from $F_{\text {ENTO }}$ were separated and quantified as well, following the protocols described above.

\section{Quantitative analysis of elements and element species. Quantification} concentration was done using ICP-MS. All samples analyses were preceded by a minimum of a five-point calibration curve spanning the entire concentration range of interest. The calibration curves associated with each element were standardized by linear regression, resulting in a response factor. All results were instrument blank corrected to account for any operational bias. Ongoing instrument performance was monitored by the analysis of continuing calibration verification standards and continuing calibration blanks. Results are presented as average with s.e.

Analysis of Entotheonella sp. by TEM. To analyse cell structure with TEM, Entotheonella sp. fixed in $2.5 \%$ glutaraldehyde (in CMF-ASW) were washed twice in $50 \mathrm{mM}$ phosphate buffered saline (PBS) $(\mathrm{pH}=8.0)$ and the cells were postfixed in $1 \% \mathrm{OsO}_{4}$ in $\mathrm{PBS}$ for $2 \mathrm{~h}$ at $4{ }^{\circ} \mathrm{C}$. Dehydration was carried out in graded ethanol followed by incubation in propylene oxide and embedding in glycidyl ether at the Instrumentation and Service Center of the Department of Life Sciences, Tel Aviv University. Thin sections were mounted on Formvar/Carbon-coated grids. Sections were stained with uranyl acetate and lead citrate and viewed under TEM (FEI Tecnai, USA) at the Weizmann Institute Electron Microscopy Unit.

Analysis of crystalline material using TEM was conducted on freeze-dried Entotheonella sp. A TEM sample of $F_{\text {ENTO }}$ was prepared using an FEI Strata $400 \mathrm{~S}$ FIB equipped with a high-precision piezoelectric specimen stage with a $100 \mathrm{~mm}$ stroke along the $x$ and $y$ axes, an in situ nano-manipulator (Omniprobe; AutoProb 200) sample extraction system for lift-out TEM specimen preparation, and flip-stage pivoting TEM grid mount. TEM investigation was carried out at the Technion, using a Titan FEI (S)TEM with a dedicated platform for corrector and monochromator technologies, which enables a resolution of $0.7 \AA$. Imaging was performed at the acceleration voltage of $300 \mathrm{keV}$.

Membrane staining. We stained membranes of Entotheonella sp. filaments using $\mathrm{DiOC}_{6}$ following a protocol developed for other bacteria ${ }^{53}$. We incubated live cells in CMF-ASW with $2.5 \mu \mathrm{g} \mathrm{ml}^{-1} \mathrm{DiOC}_{6}$ for $15 \mathrm{~min}$ (shaking in the dark at room temperature). Following incubation, we washed the cells and mounted them on glass slides in CMF-ASW. We observed the cells using a confocal microscope (Zeiss). Fluorescence of $\mathrm{DiOC}_{6}$ was detected at an excitation of $482 \mathrm{~nm}$ and emission of $504 \mathrm{~nm}$. The fluorescence image was overlaid on a DIC image to better localize the stain in the filaments. Additionally, a Z-stack series ( 17 slices of $0.3 \mu \mathrm{m}$ ) with only fluorescent filters were acquired for selected filaments.

XRPD of Entotheonella sp. and Rietveld analysis. An aliquot of $F_{\text {ENTO }}$ was used for XRD analysis. Powders were characterized by high-resolution X-ray powder diffraction (XRPD) utilizing a synchrotron source. Diffraction measurements were conducted at the ID22 beam line of the European Synchrotron Research Facility (ESRF, Grenoble, France) equipped with a double-crystal monochromator and crystal analyser optical elements in the incident and diffracted beams, respectively, at a wavelength of 0.476798 (8) $\AA$. Instrument calibration was performed using NIST silicon standards, and final instrumental contribution to the full-width at half-maximum did not exceed $0.004^{\circ} 2 \theta$ (ref. 54). The samples were loaded into $1 \mathrm{~mm}$ diameter borosilicate glass capillaries rotating during the measurements at a rate of 60 r.p.s. to avoid intensity spikes from the individual grains subjected to quasiparallel beam irradiation. The diffracted beam was monochromatized and collected using a multianalyser stage equipped with a nine-point detector (for further information see, http://www.esrf.eu/id22/technical-description). Nine diffractograms, obtained from each detector, were binned in a $2 \theta$ /intensity diffractogram. The use of the advanced analysing optics resulted in diffraction spectra of superior quality.

Rietveld quantitative phase analysis was applied to collected diffractograms to determine weight quantity of the crystalline phases present in the $F_{\text {ENTO }}$ sample. The analysis was performed using the GSAS-II software ${ }^{55}$.

X-ray microprobe. Entotheonella sp. samples for hard X-ray microprobe analyses under cryogenic conditions were flash frozen onto carbon-coated copper 200-mesh grids at the EM unit (Weizmann Institute of Science, Israel) ${ }^{56}$. Grids were glow discharged for $45 \mathrm{~s}$ before application of sample. Cells in CMF-ASW were resuspended until reaching homogenous suspension and then $5 \mu \mathrm{l}$ were placed on the grid. Grids were blotted (5s) and plunged into liquid ethane using a Leica EM-GP automated plunger (Leica Microsystems) and stored in liquid nitrogen until measurements. Arsenic and barium bearing standard compounds were either mounted on carbon-coated copper 200-mesh grids TEM Cu grids or on $\mathrm{Si}_{3} \mathrm{~N}_{4}$ windows (SiMPore Inc.). Three Entotheonella sp. sample grids with a minimum of two regions per grid were analysed.

$\mu \mathrm{XRF}$ mapping, $\mu \mathrm{XRD}$ and X-ray absorption spectroscopy (XAS) measurements were conducted at ALS bending magnet beamline 10.3.2 $(2.1-17 \mathrm{keV}$ ) with the storage ring operating at $500 \mathrm{~mA}$ and $1.9 \mathrm{GeV}$ (ref. 57). All data were recorded at $95^{\circ} \mathrm{K}$ using a custom cryogenic setup (Instec Inc.) that allows for the transfer of frozen samples following procedures described in details elsewhere ${ }^{58}$. Radiation damage was not observed under these conditions. $\mu$ XRF elemental distribution maps and $\mu \mathrm{XRF}$ spectra on each pixel were collected at $12,066 \mathrm{eV}$. Few elemental maps were also recorded at 5,347 eV above the $\mathrm{Ba}_{3}$ edge to better detect $\mathrm{Ca}, \mathrm{P}$ and $\mathrm{S}$. Beam spot size was $3 \times 3 \mu \mathrm{m}^{2}$ with pixel size $1 \times 1 \mu \mathrm{m}^{2}$ or to $2 \times 2 \mu \mathrm{m}^{2}$ and counting times $80-120 \mathrm{~ms}$ per pixel. Fluorescence emission counts were recorded using a 7-element Ge solid-state detector (Canberra) and XIA electronics. Arsenic chemical maps were taken in multienergy per line mode, at 11,830 (pre-edge background), 11,868 (As(-I) sulfides) and 11,869 (As(III) sulfides), 11,871 (arsenite), 11,875 (arsenate) and 11,979 eV (postedge, total As). These energies were chosen to investigate the distribution of $\mathrm{As}(\mathrm{III}), \mathrm{As}(\mathrm{V})$ and sulfides, but do not allow to distinguish sodium arsenate from calcium arsenate. Chemical maps shown were deadtime corrected and fitted using $\mathrm{As}_{2} \mathrm{O}_{3}$ as a proxy for As(III) and pharmacolite as a proxy for As(V).

Arsenic $\mathrm{K}$ edge $\mu \mathrm{XAS}$ spectra were recorded in fluorescence mode by continuously scanning the Si ( 1111 ) monochromator (Quick XAS mode) from 11,774 to $12,580 \mathrm{eV}$, with $0.5 \mathrm{eV}$ steps in the XANES region. Spectra were calibrated using the white line of a $\mathrm{Na}_{2} \mathrm{HAsO}_{4}$ powder standard set at $11,875 \mathrm{eV}$, recorded at room temperature in transmission mode. All data were processed using the LabVIEW custom BL 10.3.2 software and standard procedures described elsewhere ${ }^{59}$. All reference and sample XANES spectra were carefully postedge normalized up to $12,178 \mathrm{eV}$. Least-squares linear combination fitting of the XANES spectra ${ }^{60}$ was performed using a large spectral database of arsenic compounds (64 compounds) from ALS beamline 10.3.2 and procedures described elsewhere ${ }^{58}$

Arsenic standards we used: sodium arsenate at $\mathrm{pH} 8.2$ (aqueous $1 \mathrm{M}$, $\mathrm{Na}_{2} \mathrm{HAsO}_{4} \cdot 7 \mathrm{H}_{2} \mathrm{O}$; Sigma; CAS no. 10048-95-0), calcium arsenate (powder, $\mathrm{As}_{2} \mathrm{Ca}_{3} \mathrm{O}_{8}$; Alpha Chemicals; CAS no. 7778-44-1), pharmacolite (crushed mineral, $\mathrm{CaHAsO}_{4} \cdot 2\left(\mathrm{H}_{2} \mathrm{O}\right)$, provided by the Mineral Collection of the Earth and Planetary Science Department, UC Berkeley) and barium arsenate (precipitate). Barium arsenate was prepared in the lab and made from a $\mathrm{BaCl}_{2}$ solution (Sigma; $0.1 \mathrm{M}$; CAS no. 10361-37-2) and sodium arsenate (Sigma). As(V) was dissolved in $\mathrm{diH}_{2} \mathrm{O}$ to a concentration of $0.1 \mathrm{M}$. Equal volumes of the solutions were mixed and precipitation followed. The precipitate was collected by centrifugation and freeze-dried. Barium and sodium arsenate were recorded at $95^{\circ} \mathrm{K}$ in transmission mode; pharmacolite and calcium arsenate were recorded at $95^{\circ} \mathrm{K}$ in fluorescence mode. $\mathrm{As}_{2} \mathrm{O}_{3}$ was recorded at room temperature in transmission mode. 
Microdiffraction patterns were collected in transmission mode with a CCD camera (Bruker APEX2) at $17 \mathrm{keV}(\lambda=0.729 \AA)$ using a beam spot size of $12 \times 6 \mu \mathrm{m}^{2}$ and exposure time of $240 \mathrm{~s}$. Calibration of the camera distance was obtained using an alumina $\left(\alpha-\mathrm{Al}_{2} \mathrm{O}_{3}\right)$ powder standard and Fit2D software ${ }^{61}$. Fit2D was also used to obtain one-dimensional XRD profiles from the radial integration of $2 \mathrm{D}$ patterns. These data were then indexed using Jade 9 software (Materials Data Inc.) and the ICDD PDF-4+ and MINCRYST crystallographic databases.

Vitality staining of Entotheonella sp. We stained Entotheonella sp. filaments with CFDA/SE ${ }^{62}$ to assess their viability. We pelleted cells from CMF-ASW and resuspended them in PBS, adding CFDA/SE (50 $\mathrm{mM}$ in dimethylsulphoxide) to a final concentration of $100 \mu \mathrm{M}$. We followed this by stirring the suspended cells and cycling the temperature between $25^{\circ} \mathrm{C}$ and $37^{\circ} \mathrm{C}(15 \mathrm{~min}$ each $)$ for $2.5 \mathrm{~h}$. After temperature treatment we harvested the cells by centrifugation, washed and incubated them in marine broth $\left(5 \mathrm{gl}^{-1}\right.$ bactopeptone, $1^{\mathrm{gl}^{-1}}$ yeast extract in ASW, $\mathrm{pH}=8.2$ ) at $15^{\circ} \mathrm{C}$ with shaking for $48 \mathrm{~h}$. Following incubation, we again harvested cells by centrifugation, washed them in PBS and mounted them on glass slides in $70 \%$ glycerol CMF-ASW. We observed the cells with a confocal microscope (Zeiss) for fluorescence at an excitation wavelength of $492 \mathrm{~nm}$ and emission of $517 \mathrm{~nm}$. The fluorescence image was overlaid on a differential interference contrast (DIC) image to assist localization of the stain in the filaments.

Cryo-SEM of Entotheonella sp. Sample preparation and observation was conducted at the Electron Microscopy Unit at the Weizmann Institute of Science. We transferred a live sample of Entotheonella sp. in CMF-ASW to the EM unit within $24 \mathrm{~h}$ of sampling. There we preserved the sample by high-pressure freezing (HPM 10; BAL-TEC, USA). Before observation, we fractured the samples in a freeze fracture device (BAF 60; BAL-TEC, USA). We observed Entotheonella sp. in an Ultra 55 fully digital field emission scanning electron microscope microscope (Zeiss) with a Leica cryo stage (AG, Liechtenstein, Germany), exposing the filaments by light heat milling.

Statistical analysis. Sample size for quantitative analysis (total element concentration and arsenic species) was decided after a preliminary test with minimal sample size $(n=3)$. Following the analysis, separation methods were further optimized so the original samples were not included analysis.

Statistical analysis was performed using $\mathrm{R}$ statistics ${ }^{63}$ with RStudio IDE (RStudio, USA). Significant values for all tests were regarded for $P$ value $<0.05$. All measurements were tested for their fit to normal distribution (Shapiro-Wilk test). When we could not assume normal distribution, parametric tests with permutations were conducted. Permutations enabled the use of the stronger parametric tests using the true distribution of the sample by subsampling.

Differences in total arsenic concentration, total barium within arsenic species and among arsenate were tested by permuted ANOVA, using the lmPerm package $^{64}$, and Tukey's post hoc test to assign groups of significance.

Difference in sphere volume, in total barium concentration between $F_{\text {ENTO }}$ and $F_{\text {SC }}$, differences in weight $\%(\mathrm{Ba}, \mathrm{C}, \mathrm{As}$ and $\mathrm{N})$ between the mineral wall and core, and difference in atomic or weight ratios of elements (Ba:S, Ba:As, $\mathrm{As}(\mathrm{V}): \mathrm{S}(\mathrm{aq})$, $\mathrm{As}(\mathrm{V}): \mathrm{P}(\mathrm{aq})$ ) were tested using permutation test based on $\mathrm{T}$ distribution, using Perm and Deducer.

Data availability. The authors declare that all relevant data supporting the findings of this study are available within the article and its Supplementary Information Files, or from the corresponding author on request.

\section{References}

1. Oremland, R. S. \& Stolz, J. F. The ecology of arsenic. Science 300, 939-944 (2003).

2. Dehairs, F., Chesselet, R. \& Jedwab, J. Discrete suspended particles of barite and the barium cycle in the open ocean. Earth Planet. Sci. Lett. 49, 528-550 (1980).

3. Neff, J. M. Ecotoxicology of arsenic in the marine environment. Environ. Toxicol. Chem. 16, 917-927 (1997).

4. Menzie, C. A., Southworth, B., Stephenson, G. \& Feisthauer, N. The importance of understanding the chemical form of a metal in the environment: the case of barium sulfate (barite). Hum. Ecol. Risk Assess. 14, 974-991 (2008).

5. Slyemi, D. \& Bonnefoy, V. How prokaryotes deal with arsenic. Environ. Microbiol. Rep. 4, 571-586 (2012).

6. Chow, T. J. \& Goldberg, E. D. On the marine geochemistry of barium. Geochim. Cosmochim. Acta 20, 192-198 (1960).

7. Rainbow, P. S. Trace metal concentrations in aquatic invertebrates: why and so what? Environ. Pollut. 120, 497-507 (2002).

8. Taylor, M. W., Radax, R., Steger, D. \& Wagner, M. Sponge-associated microorganisms: evolution, ecology, and biotechnological potential. Microbiol. Mol. Biol. Rev. 71, 295-347 (2007).

9. Gili, J.-M. \& Coma, R. Benthic suspension feeders: their paramount role in littoral marine food webs. Trends Ecol. Evol. (Personal edition) 13, 316-321 (1998).
10. De Goeij, J. M. et al. Surviving in a marine desert: the sponge loop retains resources within coral reefs. Science 342, 108-110 (2013).

11. Ribes, M., Coma, R., Atkinson, M. J. \& Kinzie, R. A. Sponges and ascidians control removal of particulate organic nitrogen from coral reef water. Limnol. Oceanogr. 50, 1480-1489 (2005).

12. Maldonado, M. et al. Siliceous sponges as a silicon sink: an overlooked aspect of benthopelagic coupling in the marine silicon cycle. Limnol. Oceanogr. 50, 799-809 (2005).

13. Weisz, J. B., Lindquist, N. \& Martens, C. S. Do associated microbial abundances impact marine demosponge pumping rates and tissue densities? Oecologia 155 , 367-376 (2008).

14. Mayzel, B., Aizenberg, J. \& Ilan, M. The elemental composition of demospongiae from the Red Sea, Gulf of Aqaba. PLoS ONE 9, e95775 (2014).

15. Cebrian, E., Uriz, M.-J. \& Turon, X. Sponges as biomonitors of heavy metals in spatial and temporal surveys in northwestern mediterranean: multispecies comparison. Environ. Toxicol. Chem. 26, 2430-2439 (2007).

16. Pan, K., Lee, O. O., Qian, P. Y. \& Wang, W. X. Sponges and sediments as monitoring tools of metal contamination in the eastern coast of the Red Sea, Saudi Arabia. Mar. Pollut. Bull. 62, 1140-1146 (2011).

17. Patel, B., Balani, M. C. \& Patel, S. Sponge 'sentinel' of heavy metals. Sci. Total Environ. 41, 143-152 (1985).

18. Keren, R., Lavy, A., Mayzel, B. \& Ilan, M. Culturable associated-bacteria of the sponge Theonella swinhoei show tolerance to high arsenic concentrations. Front. Microbiol. 6, 154 (2015).

19. Keren, R., Lavy, A. \& Ilan, M. Increasing the Richness of culturable arsenic-tolerant bacteria from Theonella swinhoei by addition of sponge skeleton to the growth medium. Microb. Ecol. 71, 873-886 (2016).

20. Ilan, M., Gugel, J. \& Van Soest, R. W. M. Taxonomy, reproduction and ecology of new and known Red Sea sponges. Sarsia 89, 388-410 (2004).

21. Magnino, G., Sara, A., Lancioni, T. \& Gaino, E. Endobionts of the coral reef sponge Theonella swinhoei (Porifera, Demospongiae). Inverteb. Biol. 118, 213-220 (1999).

22. Wilson, M. C. et al. An environmental bacterial taxon with a large and distinct metabolic repertoire. Nature 506, 58-62 (2014).

23. Schmidt, E. W., Obraztsova, A. Y., Davidson, S. K., Faulkner, D. J. \& Haygood, M. G. Identification of the antifungal peptide-containing symbiont of the marine sponge Theonella swinhoei as a novel delta-proteobacterium, 'Candidatus Entotheonella palauensis'. Mar. Biol. 136, 969-977 (2000).

24. Phillips, D. J. H. \& Rainbow, P. S. Strategies of trace metal sequestration in aquatic organisms. Mar. Environ. Res. 28, 207-210 (1989).

25. Yahel, G., Sharp, J. H., Marie, D., Hase, C. \& Genin, A. In situ feeding and element removal in the symbiont-bearing sponge Theonella swinhoei: bulk DOC is the major source for carbon. Limnol. Oceanogr. 48, 141-149 (2003).

26. Bazylinski, D. A. \& Frankel, R. B. in Biomineralization Reviews in Mineralogy and Geochemistry Vol. 54 (eds Dove, P. M., DeYoreo, J. J. \& Weiner, S.) 217-247 (Mineralogical Soc America, 2003).

27. Frankel, R. B. \& Bazylinski, D. A. Biologically induced mineralization by bacteria. Rev. Mineral. Geochem. 54, 95-114 (2003).

28. Edwards, K. J. \& Bazylinski, D. A. Intracellular minerals and metal deposits in prokaryotes. Geobiology 6, 309-317 (2008).

29. Konhauser, K. O. Diversity of bacterial iron mineralization. Earth Sci. Rev. 43, 91-121 (1998)

30. Peng, X. T. et al. Intracellular and extracellular mineralization of a microbial community in the Edmond deep-sea vent field environment. Sediment. Geol. 229, 193-206 (2010).

31. Rietveld, H. M. A profile refinement method for nuclear and magnetic structures. J. Appl. Crystallogr. 2, 65-6 (1969).

32. Smith, P. G. et al. X-ray absorption near-edge structure analysis of arsenic species for application to biological environmental samples. Environ. Sci. Technol. 39, 248-254 (2005).

33. Arai, Y., Elzinga, E. J. \& Sparks, D. L. X-ray absorption spectroscopic investigation of arsenite and arsenate adsorption at the aluminum oxide-water interface. J. Colloid Interface Sci. 235, 80-88 (2001).

34. Hohmann, C. et al. Molecular-level modes of As binding to Fe(III) (oxyhydr)oxides precipitated by the anaerobic nitrate-reducing $\mathrm{Fe}$ (II)-oxidizing Acidovorax sp. strain BoFeN1. Geochim. Cosmochim. Acta 75, 4699-4712 (2011).

35. Finch, A. A., Allison, N., Steaggles, H., Wood, C. V. \& Mosselmans, J. F. W. $\mathrm{Ba}$ XAFS in Ba-rich standard minerals and the potential for determining $\mathrm{Ba}$ structural state in calcium carbonate. Chem. Geol. 270, 179-185 (2010).

36. Escalante, G. et al. Arsenic resistant bacteria isolated from arsenic contaminated river in the Atacama Desert (Chile). Bull. Environ. Contam. Toxicol. 83, 657-661 (2009).

37. Stolz, J. F., Basu, P., Santini, J. M. \& Oremland, R. S. Arsenic and selenium in microbial metabolism*. Annu. Rev. Microbiol. 60, 107-130 (2006).

38. Weiner, S. \& Dove, P. M. in Biomineralization Reviews in Mineralogy and Geochemistry Vol. 54 (eds Dove, P. M., DeYoreo, J. J. \& Weiner, S.) 1-29 (Mineralogical Society of America, 2003) 
39. Chávez-Capilla, T., Maher, W., Kelly, T. \& Foster, S Evaluation of the ability of arsenic species to traverse cell membranes by simple diffusion using octanolwater and liposome-water partition coefficients. J. Environ. Sci. 49, 222-232 (2016).

40. Morth, J. P. \& Perdreau, H. in Encyclopedia of Metalloproteins (eds Kretsinger, R H., Uversky, V. N. \& Permyakov, E. A.) 241-244 (Springer New York, 2013).

41. Erez, J. in Biomineralization Reviews in Mineralogy \& Geochemistry Vol. 54 (eds Dove, P. M., DeYoreo, J. J. \& Weiner, S.) 115-149 (Mineralogical Society of America, 2003).

42. Lonhienne, T. G. A. et al. Endocytosis-like protein uptake in the bacterium Gemmata obscuriglobus. Proc. Natl Acad. Sci. USA 107, 12883-12888 (2010).

43. Yamaoka, Y., Carmona, M. L., Oclarit, J. M., Jin, K. \& Shibata, Y. Characterization of water-soluble organoarsenic compounds in marine sponges. Appl. Organomet. Chem. 20, 545-548 (2006).

44. Banerjee, S., Datta, S., Chattyopadhyay, D. \& Sarkar, P. Arsenic accumulating and transforming bacteria isolated from contaminated soil for potential use in bioremediation. J. Environ. Sci. Health Part A 46, 1736-1747 (2011).

45. Yin, X. X., Wang, L. H., Bai, R., Huang, H. \& Sun, G. X. Accumulation and transformation of arsenic in the blue-green alga Synechocysis sp PCC6803. Water Air Soil Pollut. 223, 1183-1190 (2012).

46. Basu, A., Saha, D., Saha, R., Ghosh, T. \& Saha, B. A review on sources, toxicity and remediation technologies for removing arsenic from drinking water. Res. Chem. Intermed. 40, 447-485 (2014).

47. Newman, D. K., Beveridge, T. J. \& Morel, F. Precipitation of arsenic trisulfide by Desulfotomaculum auripigmentum. Appl. Environ. Microbiol. 63, 2022-2028 (1997).

48. Saier, Jr M. H. \& Bogdanov, M. V. Membranous organelles in bacteria. J. Mol. Microbiol. Biotechnol. 23, 5-12 (2013).

49. Bewley, C. A., Holland, N. D. \& Faulkner, D. J. Two classes of metabolites from Theonella swinhoei are localized in distinct populations of bacterial symbionts. Experientia 52, 716-722 (1996).

50. de Chaumont, F. et al. Icy: an open bioimage informatics platform for extended reproducible research. Nat. Meth. 9, 690-696 (2012).

51. EPA. The SW-846 Clcompendium method 3050B: acid digestion of sediments, sludges, and soils, revision 2 (1996).

52. Cornelia, H. \& Britta, P.-F. Thioarsenate transformation by filamentous microbial mats thriving in an alkaline, sulfidic hot spring. Environ. Sci. Technol. 46, 4348-4356 (2012).

53. Herskovits, A. A., Shimoni, E., Minsky, A. \& Bibi, E. Accumulation of endoplasmic membranes and novel membrane-bound ribosome-signal recognition particle receptor complexes in Escherichia coli. J. Cell Biol. 159, 403-410 (2002).

54. Fitch, A. N. The high resolution powder diffraction beam line at ESRF. J. Res. Natl Inst. Stand. Technol. 109, 133-142 (2004).

55. Toby, B. H. GSAS-II: the genesis of a modern open-source all purpose crystallography software package. J. Appl. Crystallogr. 46, 544 (2013).

56. Wolf, S. G., Houben, L. \& Elbaum, M. Cryo-scanning transmission electron tomography of vitrified cells. Nat. Methods 11, 423 (2014).

57. Marcus, M. A. et al. Beamline 10.3. 2 at ALS: a hard X-ray microprobe for environmental and materials sciences. J. Synchrotron Radiat. 11, 239-247 (2004).

58. Fakra, S. C. et al. Correlative cryogenic spectro-microscopy to investigate Selenium bioreduction products. Environ. Sci. Technol. doi:10.1021/ acs.est.5b01409 (2015).

59. Kelly, S., Hesterberg, D. \& Ravel, B. Analysis of soils and minerals using X-ray absorption spectroscopy. Methods Soil Anal Part 5, 387-463 (2008).

60. Castillo-Michel, H. et al. Localization and speciation of arsenic in soil and

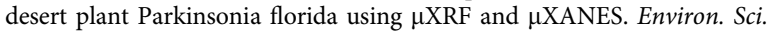
Technol. 45, 7848-7854 (2011).

61. Hammersley, A., Svensson, S., Hanfland, M., Fitch, A. \& Hausermann, D. Two-dimensional detector software: from real detector to idealised image or two-theta scan. Int. J. High Pressure Res. 14, 235-248 (1996).

62. Fuller, M. E. et al. Development of a vital fluorescent staining method for monitoring bacterial transport in subsurface environments. Appl. Environ. Microbiol. 66, 4486-4496 (2000).
63. R Foundation for Statistical Computing. R: A Language and Environment for Statistical Computing V. 2.15.1 (R Foundation for Statistical Computing, 2012).

64. R Development Core Team. A language and environment for statistical computing. $R$ Foundation for Statistical Computing (Vienna, Austria, 2008). http://www.R-project.org.

\section{Acknowledgements}

The authors would like to acknowledge the Interuniversity Institute, Eilat and its staff for the ongoing support and use of their facilities. We thank Y. Zilberstein for assistance with confocal microscope; L. Amitai and A. Brener for assistance with SEM-EDS; B-nano for use of their airSEM; T. Cohen-Hyams for assistance with FIB; Y. Kauffmann for assistance with TEM; B. Wozniak for assistance and consultation for ICP-MS and IC-ICP-MS; E. Shimoni for assistance with cryo-SEM and TEM; S.G. Wolf for cryopreservation of Entotheonella sp.; M.A. Marcus for support and the Advanced Light Source for provision of beamtime; J. Piel and J.F. Banfield for constructive criticism and advice during the course of this work. The study has been partially supported by the following institutions and grants; Israel Science Foundation (grant number 957/14). The Advanced Light Source is supported by the Director, Office of Science, Office of Basic Energy Sciences, of the US Department of Energy under Contract No. DE-AC02-05CH11231. We are also indebted to the ESRF (ID22), and specifically to A. Fitch, for the support in operating the high-resolution $\mathrm{x}$-ray powder diffraction beamline. R.K. was supported by the Fellowship of the Argentina PhD Honors Program of the Smolarz Family. A.L. was supported by an Eshkol scholarship from the Israeli Ministry of Science, Technology and Space.

\section{Author contributions}

M.I. supervised the study. R.K., B.M. and M.I. designed the study with inputs from all authors. R.K., A.L. and M.I. collected and processed samples for experiments. R.K., B.M. and A.L. analysed the ICP-MS and IC-ICP-MS data. A.L. and R.K. ran statistical tests. I.P., R.K. and B.P. analysed SEM-EDS data. I.P., B.P. and A.L. performed TEM experiments, with contributions from R.K. R.K. and A.L. performed cryo-SEM and confocal microscopy analysis. D.L. and B.P. performed XRD experiments and data analysis. S.F. performed X-ray microprobe experiments and data analysis. R.K. and B.M. wrote the manuscript. All authors commented on and edited the manuscript.

\section{Additional information}

Supplementary Information accompanies this paper at http://www.nature.com/ naturecommunications

Competing financial interests: The authors declare no competing financial interests.

Reprints and permission information is available online at http://npg.nature.com/ reprintsandpermissions/

How to cite this article: Keren, R. et al. Sponge-associated bacteria mineralize arsenic and barium on intracellular vesicles. Nat. Commun. 8, 14393 doi: 10.1038/ncomms14393 (2017)

Publisher's note: Springer Nature remains neutral with regard to jurisdictional claims in published maps and institutional affiliations.

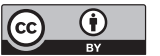

This work is licensed under a Creative Commons Attribution 4.0 International License. The images or other third party material in this article are included in the article's Creative Commons license, unless indicated otherwise in the credit line; if the material is not included under the Creative Commons license, users will need to obtain permission from the license holder to reproduce the material. To view a copy of this license, visit http://creativecommons.org/licenses/by/4.0/

C The Author(s) 2017 